\title{
Synthesis and STM Imaging of Substituted Phenylalkyl Ethers: Towards Functional Group Discrimination
}

\author{
A. J. M. Lubag, Jr., K. Kangasniemi, and I. H. Musselman \\ Department of Chemistry, University of Texas at Dallas, Richardson, TX 750830688
}

Recent scanning tunneling microscopy (STM) studies of organic adsorbates at the liquid/solid interface have focused on extracting chemical information from the atomically resolved images, including the identification of atoms [1-9] or of functional groups [8-14] within an adsorbed molecule. As the mechanism(s) by which the image contrast reveals atomic and molecular structures is still a matter of debate, STM image interpretation continues to be a challenge [7,919]. The electronic factor, which is related to the coupling between the energy levels of the adsorbate and the Fermi level of the substrate, and the geometric factor, which addresses the spatial overlap between the STM tip and functional group, have been more recently proposed as two major considerations in image contrast interpretation [11-14,18,19]. However, the possible decoupling of these two factors through bias-dependent imaging, which could enhance functional group contrast analysis $[8,9,16,20]$, presented yet another challenge.

Previous studies in our laboratory of a homologous series of para-halogenated phenyloctadecyl ethers (X-POEs, where $\mathrm{X}=\mathrm{H}, \mathrm{Cl}, \mathrm{Br}, \mathrm{I}$ ), physisorbed onto highly oriented pyrolytic graphite (HOPG) revealed that the tunneling process occurs through a resonance mechanism involving the energy states of the adsorbate, tip and substrate. This was supported by the bias-dependent contrast observed in the STM images resembling calculated (HyperChem) electron density contours of bonding molecular orbitals [8,9]. In the recently reported analysis of image contrast of halogens $(\mathrm{X}=\mathrm{Cl}, \mathrm{Br}, \mathrm{I})$ in $\mathrm{X}$-POEs, the halogens could be quantitatively discriminated from each other by acquiring images representing the highest occupied molecular orbital (HOMO) thereby effectively decoupling the electronic from the geometric factor [9]. It was found that the intensities of the spots for the halogen atoms followed the trend of their respective atomic radii. This demonstration of chemical sensitivity of STM was made possible by the appearance of the functional group as one bright spot and the phenyl ring as two bright spots, and one dimmer spot for the combined oxygen/alpha-carbon atoms.

In this study, X-POEs (where $\mathrm{X}=\mathrm{CN}, \mathrm{NO}_{2}, \mathrm{NH}_{2}$ ) and X-PHEs (hydroxy-terminated, parasubstituted phenylhexadecyl ethers, where $\mathrm{X}=\mathrm{CN}, \mathrm{NO}_{2}, \mathrm{NH}_{2}$ ) were synthesized to further explore the chemical specificity of STM. High-resolution bias-dependent STM images of CNPOE, CN-PHE, and $\mathrm{NO}_{2}$-POE were obtained at biases between -750 and $-1100 \mathrm{mV}$. The three monolayers afforded HOMO-resembling images that enabled quantitative discrimination of the functional groups with each other and with the previously reported halogens $(X=\mathrm{Cl}, \mathrm{Br}, \mathrm{I})$ in $\mathrm{X}$ POEs [9]. Analysis revealed that the packing geometry, including molecular and overall monolayer metrics, could aid in the functional group discrimination. For the X-POEs, it was also found that the orientation of the functional group $\left(\mathrm{CN}, \mathrm{NO}_{2}, \mathrm{Br}, \mathrm{I}\right)$ in a lamella and relative to the HOPG substrate significantly influenced its contrast [21]. 


\section{References}

[1] J. Hossick Schott and H. S. White, Langmuir 10 (1994) 486.

[2] J. Hossick Schott and H. S. White, J. Phys. Chem. 98 (1994) 291.

[3] J. Hossick Schott and H. S. White, J. Phys. Chem. 98 (1994) 297.

[4] J. C. H. Spence et al., J. Vac. Sci. Technol. B 14 (1996) 1587.

[5] P. Sautet, Surf. Sci. 374 (1997) 406.

[6] B. Voigtlander et al., Phys. Rev. B 55 (1997) R13444.

[7] B. Venkataraman et al., J. Phys. Chem. 99 (1995) 8684.

[8] H. S. Lee et al., Langmuir 14 (1998) 7475.

[9] H. S. Lee et al., Anal. Chem. 73 (2001) 5532.

[10] D. Cyr et al., J. Phys. Chem. 100 (1996) 13747.

[11] C. L. Claypool et al., J. Phys. Chem. B 101 (1997) 5978.

[12] F. Faglioni et al., J. Phys. Chem. B 101 (1997) 5996.

[13] L. Giancarlo et al., Langmuir 14 (1998) 1465.

[14] J. K. Spong et al., Nature 338 (1989) 137.

[15] D. P. E. Smith et al., Nature 344 (1990) 641.

[16] W. Mizutani et al., Appl. Phys. Lett. 56 (1990) 1974.

[17] R. Strohmaier et al., Surf. Sci. 418 (1998) 91.

[18] C. L. Claypool et al., J. Phys. Chem. B 103 (1999) 7077.

[19] C. L. Claypool et al., J. Phys. Chem. B 103 (1999) 9690.

[20] J. S. Roach et al., J. Vac. Sci. Technol., A 14 (1996) 1205.

[21] A. J. M. Lubag et al., manuscript in preparation.

[22] The support of this research by a grant from the Robert A. Welch Foundation is gratefully acknowledged.
A. X-POE:

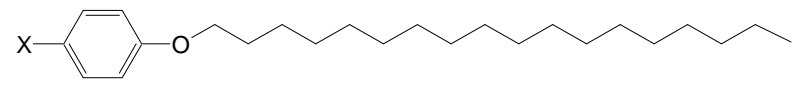
X-PHE:

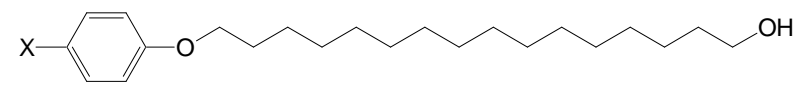

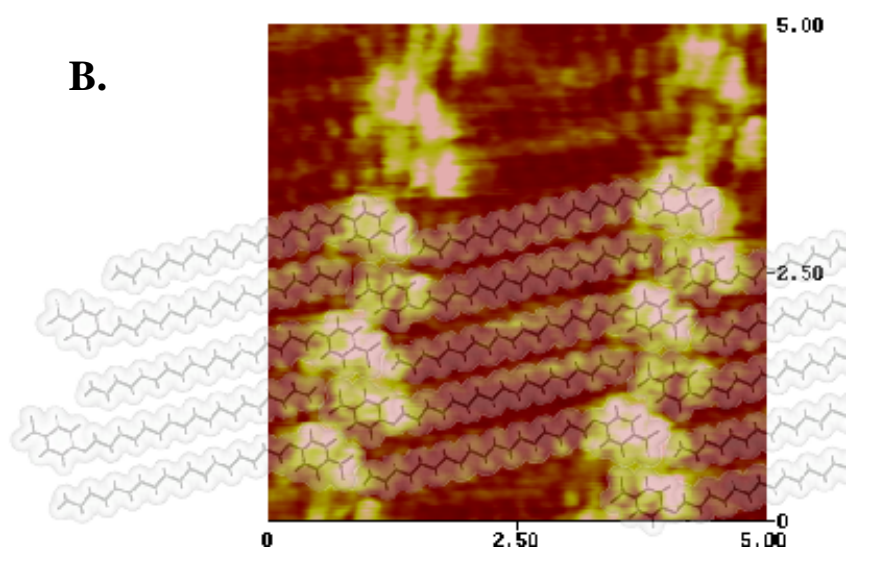

C.

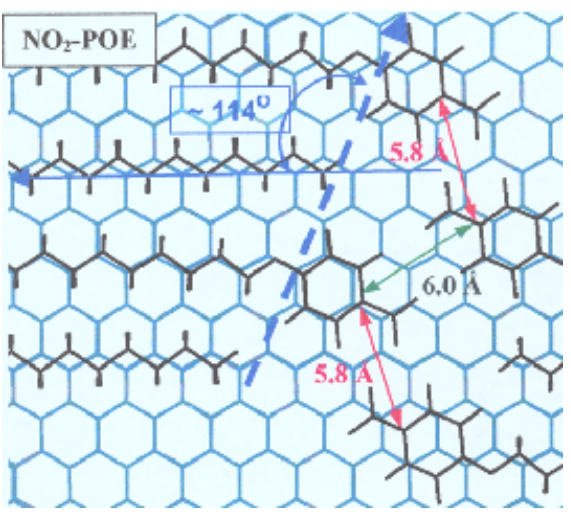

FIG 1. A. Structure of X-POEs and X-PHEs, B. STM image $\left(5 \times 5 \mathrm{~nm}^{2}\right.$, Bias = -0.91 V) of $\mathrm{NO}_{2^{-}}$ POE overlaid with HyperChem ${ }^{\circledR}$ molecular models, and C. Packing assignment of $\mathrm{NO}_{2}-\mathrm{POE}$ head groups (black) on HOPG substrate (blue). 